\title{
Mo School Abhiyan in Odisha: Towards Development of School Education
}

\author{
Niharika Panda ${ }^{1 *}$ and Laxmidhar Behera ${ }^{2}$
}

${ }^{1}$ Research Scholar and ${ }^{2}$ Professor

Department of Education, Regional Institute of Education, Bhubaneswar, Odisha, India

"Corresponding author: 4niharikapanda@gmail.com

Received: 18-06-2021 Revised: 20-07-2021 Accepted: 15-08-2021

\begin{abstract}
Development of infrastructure is the basis for quality education, whereas holistic development needs a compilation of social, emotional, economical aspects that can bring change in the existing scenario of school education. 'Mo School Abhiyan' in Odisha is an innovative project to boost the school education with the help of contributions from alumni of any school with which they have some emotional attachments. Quality education needs investments which strengthens a society's wealth and growth, where individuals can improve their own personal efficacy and productivity. In 'Mo School Abhiyan', the contributors have the freedom to support the school education by any means they could with ease. This platform is the first one of its own kind and received extensive support from multiple stakeholders for the holistic development of School education in Odisha. This article outlines the concept, genesis, objectives, achievements of the programme, improvements in school education, and responses from stakeholders on the introduction of 'Mo School Abhiyan' to the system. The impact of 'Mo School Abhiyan' on the school education ecosystem of Odisha is described. At last, it outlines some of the emerging challenges and suggestions to achieve the goals of the project.
\end{abstract}

Keywords: Mo School Abhiyan, school education, holistic development, alumni, reform

For realization of the goal of imparting quality education to all, several policies and programmes like Sarva Shiksha Abhiyan, Rashtriya Madhyamik Shiksha Abhiyan, Kasturba Gandhi Balika Vidyalaya, Eklavya Model Residential School etc. were initiated by the Government. However, there is no single programme that guarantees optimum educational access rates and improving the quality. It was self-evident from the educational gap realized in a number of aspects of the system of school education. This is reflected by a range of indicators, from the stakeholders to the Government. So, there has always been scope for a better initiative to be taken for ensuring holistic development in school education. The NEP-2020 in its Part-I section of School Education focused on the specific dimension for, "Curtailing Dropout Rates and
Ensuring Universal Access to Education at All Levels" and provided suggestions to take measures for the more involvement of the community to the school education. This was clearly reflected in the following vision of NEP-2020:

\begin{abstract}
"Efforts will be made to involve community and alumni in volunteer efforts for enhancing learning by providing at schools: one-on-one tutoring; the teaching of literacy and holding of extra-help sessions; teaching support and guidance for educators; career guidance and mentoring to students; etc." (NEP, 2020, p. 11).
\end{abstract}

How to cite this article: Panda, N. and Behera, L. (2021). Mo School Abhiyan in Odisha: Towards Development of School Education. Educational Quest: An Int. J. Edu. Appl. Soc. Sci., 12(2): 85-93.

Source of Support: None; Conflict of Interest: None (क) क 
To do so the NEP-2020 also threw light on the identification and communication of resourceful citizens. This was reflected as:

"In this regard, the support of active and healthy senior citizens, school alumni and local community members will be suitably garnered. Databases of literate volunteers, retired scientists/government/semi government employees, alumni, and educators will be created for this purpose."(NEP, 2020, p. 11)

'Mo School Abhiyan' is an initiative taken by the Government of Odisha towards establishing a connection between school education and the community members in general and the alumni in particular. The emotional attachment of the alumni with the school motivates them to do something for the improvement of the school education system. This aspect of the community was realized and the novel initiative emerged in the state of Odisha.

\section{Overview of Textual Data}

The textual data overview relating to the role of alumni, role of community in school education conducted by researchers around the globe has stated certain general findings in the area of institutional development, improvement of physical infrastructure of the educational institute, academic performance of the students and the holistic development of higher education as well as in the school education system. The underlying concepts of the present study have evolved from the literature. The researcher has used newspaper articles, policy documents, handbooks, articles, journals, web sites as reference material in the present study.

Srinivasan (Sept. 9, 2019) in the article "The benefits of a strong alumni network" of The Hindu emphasized the importance of alumni in three different aspects such as: building brand, grading and giving back and skill development. The article provided the data related to the notable contributions that helped in the development of educational institutions in India holistically.

Moody (Dec. 8, 2020) has provided the data regarding the donations of the alumni for the development of the institution in the article, "10 Colleges Where the Most Alumni Donate" of U.S. News, where it was reported that,

"Colleges see alumni donations as essential to supporting their educational mission. Such contributions also signal satisfaction; successful grads are likely to give back to their school, which is why the alumni giving rate average factors into the U.S. News Best Colleges rankings."

Tulankar and Grampurohit (2020) reported that "It seems to be a common practice in the universities in the United States to invite their distinguished alumnus as a guest of honor on their graduation ceremonies thereby projecting him/her as a role model for the fresh graduates. Similarly, many universities in the states award their alumni who have become entrepreneurs no matter big or small and have contributed for national development. In reputed universities around the globe alumni have been playing an important role in University Development, in curricular development, in employability, in transformation of higher education and in continuous quality improvement".

It became self-evident that the involvement of alumni, parents, and community into the education system absolutely had a positive impact towards the reformation and holistic development of the entire education ecosystem in the country.

\section{Mo School Abhiyan}

The project known as 'Mo School Abhiyan' was initiated and lunched on $14^{\text {th }}$ November 2017 by Government of Odisha to provide a platform for sharing, contributing resources to improve the school education in Odisha. This idea emerged from the desires of alumni who wanted to help in bringing improvement in the education of their alma maters. Since the initiation of the project, it received a huge positive response from all the stakeholders as well as from the private sector corporates, philanthropists, social impact organizations, institutions, high level officials, and others not only from Odisha or India but from alumni who reside abroad also.

'Mo School Abhiyan' rests on five pillars: Connect, Collaborate, Contribute, Create and finally, Celebrate; this statement was found in the archives of official website of School and Mass Education, Odisha (https://sme.odisha.gov.in/sites/default/ files/2020-08/Mo_School.pdf). It provides a platform for contributing any kind of resources whether it is monetary or knowledge sharing. It has the principle of providing a framework for working collaboratively in relation to the following aspects of 
school education (i) improving school infrastructure and school development (ii) improving student well-being, and (iii) improving student learning.

\section{Research Questions}

This study was guided by the following research questions:

1. What is the conceptual framework of the project Mo School Abhiyan?

2. How is the programme Mo School Abhiyan carried out?

3. What are the emerging challenges in implementing the programme?

4. What are the suggestions and measures for effectiveness of the programme?

\section{Methodology}

As an initiative of a new kind in the country, this 'Mo School Abhiyan' is a programme which requires an in-depth understanding of variables, issues, and problems. Thus, a case study approach was adopted to have in-depth information. Here explanatory questions regarding the programme were answered from relevant documents. Besides, the perspectives of stakeholders form the basis for studying the challenges and success stories about the Mo school Abhiyan.

\section{Tools and Techniques}

Case study was useful to study how the programme has been implemented as a particular and innovative initiative named as 'Mo School Abhiyan' in the State of Odisha, India. Here, the researcher was focusing on studying the process of the specific programme and its effect on school education. Case study was quite appropriate for the evaluation of the innovative initiative considering it a case. The research was carried out by using multiple case study method. The participants of the research were the four alumni, three teachers, two head teachers, one education officer and two community members. Informal interviews were conducted by the researcher and verified some cases by personal field visits. The collected data from the above sources were analyzed carefully and then interpreted systematically in the paper.

\section{Mo School Abhiyan: The Supporting Concepts from Textual Data}

Alumni of an institution have the ability to influence, motivate, and contribute to their alma mater. They can be the game changer to build an ecosystem for holistic development in the school education scenario. The attitude of giving back to the institution which instilled the learning abilities, laid the foundation for future- is the considerably basic idea for creating a scope for the volunteers to contribute by the project of 'Mo School Abhiyan' in Odisha.

NEP-2020 emphasized on Efficient Resourcing and suggested ideas to promote social interaction that reflected in the following suggestions,

"The school should be a point of celebration and honour for the whole community. The dignity of the school as an institution should be restored and important dates, such as the foundation day of the school, will be celebrated along with the community and the list of important alumni may be displayed and honoured." (NEP, 2020, p. 11)

One of the five pillars of the foundation of 'Mo School Abhiyan' is 'Celebrate', which has reflections of NEP-2020 suggestions on honouring the alumni. In this 'Celebrate' programme the objective was fulfilled as mentioned in official website of School and Mass Education, Odisha.

"To bring together past and present students and teachers to honour school memories and felicitate Alumni and Alumni Associations that have shown a genuine interest in leveraging the Programme, Mo School Abhiyan organizes a day-long celebration at the school level during January every year." ( $p .4)$

The alumni have the great potential to conduct fundraising. It has an equally great ability to build a skills and knowledge sharing network (Tulankar \& Grampurohit, 2020). According to the revised guidelines of National Assessment and Accreditation Council (NAAC, 2020).

"The Alumni are a strong support to the institution. An active Alumni Association can contribute in academic matters, student support as well as mobilization of resources - both financial and non-financial. The institution nurtures the alumni association/chapters to facilitate them to contribute significantly to the 
development of the institution through financial and non-financial means." (NAAC, 2020, p. 19)

The above concepts lay down the foundation for creating a platform where anyone can volunteer for the holistic development of school education with their emotions.

\section{Mo School Abhiyan: Objectives}

The objectives of 'Mo School Abhiyan' (https:// moschool.in/about-mo-school/) is to;

Foster and facilitate volunteerism to give back to alma maters.

$\square$ Provide a platform for individuals (including, but not limited to, alumni), associations, social impact organizations, foundations, philanthropists, companies, and others to contribute to the development of the school ecosystem in Odisha.

$\square$ Leverage the experience, success and influence of the alumni and its vast worldwide network to impart best practices in school education.

Create an enabling environment to harness the vast human resources and intellectual capital of the State and its people.

Equip students with the physical and mental infrastructure required for multi-faceted development such that they can evolve into wholesome individuals empowered to pursue any vocation, profession, or avocation that they are passionate about.

Groom school children to become dreamers, doers, makers, growers, explorers, experimenters and entrepreneurs.

\section{Mo School Abhiyan: Strategies which triggered the Initiative}

Some strategies acted as catalyst to revamp the school education in Odisha, adopted in the project of 'Mo School Abhiyan'. Most importantly the inculcation of belongingness among the stakeholders by naming the initiative as 'Mo School Abhiyan', which literally means 'My School'. This sense of attachment instills affection as well as responsibility. The major factors that facilitated the reformation in school education under 'Mo School Abhiyan' project was,

A single globalized platform for alumni or others to contribute to their alma mater. $\square$ Financial contribution was encouraged by the Government as a matched twice amount of donated monetary resource was granted for reformation of school education.

Means of contribution were not limited to financial support only, it has also provided scope for any kind of contribution such as sharing experiences, teaching life-lessons, providing technological exposures etc.

$\square$ The Concept of 5 C: Connect, Collaborate, Contribute, Create and Celebrate.

Adopting schools by high-rank officials.

\section{Reformations in School Education by ' $M o$ School Abhiyan'}

The widely appreciated project could be seen in the facts and figures of the project progress details displayed in the official website of Mo School (https:// moschool.in/home2/).

“Meet organizations bridging Odisha's great digital divide to teach students" (Hindustan Times, July 5, 2021) article highlighted the initiative for providing learning opportunities to the learners having featured phones. Acharya, B. whose organization 'Think Zone' partnered with Odisha Government's Mo School programme for developing a homebased learning programme. Partnering with some organizations, the Government has developed different platforms to revitalize School Education on specific aspects which were observed from the following cases retrieved from the official website of School and Mass Education, Odisha as:

$\square$ Partnering with Bakul Foundation \& Tata Trusts, a set of books, stories and animation films has been provided to 18 schools in 3 southern districts by 'Mo School Abhiyan', which were selected carefully and designed according to the need and interest of the learners.

With contribution from the British High Commission, in partnership with the British Council, programmes have been set up to enrich English language proficiency of English teachers in 141 high schools of Odisha.

A UK registered charity was running Code Club in schools to inspire the next generation. Raspberry Pi Foundation partnered with the Government of Odisha in association with the 
Table 1: Progress of Mo School Abhiyan in terms of Monetary Contributions

\begin{tabular}{llllll}
\hline Date & $\begin{array}{l}\text { Executive } \\
\text { council }\end{array}$ & $\begin{array}{l}\text { Number of } \\
\text { projects approved }\end{array}$ & $\begin{array}{l}\text { Number of } \\
\text { districts }\end{array}$ & $\begin{array}{l}\text { Donor contribution } \\
\text { in INR }\end{array}$ & $\begin{array}{l}\text { Government's matching } \\
\text { grant in INR }\end{array}$ \\
\hline July 19, 2018 & First & 262 & 6 & - & $1,77,01,891$ \\
Nov 3, 2018 & Fifth & 703 & 14 & $1,94,63,776$ & $2,89,27,552$ \\
Dec 14, 2018 & Sixth & 1918 & 13 & $3,47,39,614$ & $6,94,79,228$ \\
Jan 14, 2019 & Seventh & 1398 & 16 & $3,05,55,059$ & $6,11,10,118$ \\
Feb 18, 2019 & Eighth & 1489 & 22 & 50560323.6 & 101120647.2 \\
Mar 1, 2019 & Ninth & 1214 & 20 & $3,49,00,918.5$ & $6,98,01,837$ \\
July 18, 2019 & Tenth & 489 & 18 & $1,94,65,506$ & $3,88,51,012$ \\
Aug 30, 2019 & Eleventh & 708 & 25 & $2,15,10,129$ & $4,30,20,258$ \\
Oct 29, 2019 & Twelfth & 750 & 16 & $1,30,17,108$ & $2,60,34,216$ \\
Jan 14, 2020 & Thirteen & 1065 & 21 & $2,07,55,420$ & $4,15,10,840$ \\
Feb 12, 2020 & Fourteenth & 827 & 21 & $2,69,47,705$ & $5,38,95,410$ \\
Jun 18, 2020 & Fifteenth & 490 & 20 & $1,51,01,913$ & $3,02,03,826$ \\
Aug 21, 2020 & Sixteenth & 305 & 19 & $1,41,18,949$ & $2,82,37,898$ \\
Oct 12, 2020 & Seventeenth & 236 & 15 & $1,04,74,856$ & $209,49,712$ \\
Nov 13, 2020 & Eighteenth & 1606 & 25 & $2,46,41,338$ & $4,92,82,136$ \\
Dec 4, 2020 & Nineteenth & 2657 & 28 & $3,58,50,208$ & $7,17,00,416$ \\
Dec 24, 2020 & Twentieth & 4488 & 28 & $9,12,46,505$ & $18,24,93,010$ \\
Jan 28, 2021 & Twenty first & 4701 & 30 & $10,88,42,315$ & $21,76,84,630$ \\
Feb 19, 2021 & Twenty second & 5609 & 28 & $10,80,93,334$ & $21,57,86,668$ \\
Mar 25, 2021 & Twenty third & 4116 & 28 & $9,77,90,709$ & $19,55,81,418$ \\
Apr 30, 2021 & Twenty fourth & - & 24 & 5.20 crores & 10.40 crores \\
Jun 17, 2021 & Twenty fifth & - & 23 & 5 crores & 8 crores \\
\hline
\end{tabular}

The data presented in Table 1 was collected from the secondary sources, the summary of the executive councils' reports published in the official website of 'Mo School' (https://moschool.in/home2/)..

'Mo School Abhiyan' project, creating events to foster interest in computer science among the learners.

'Mo School Abhiyan' has partnered with INFOSYS Foundation for revamping 50 numbers of 100 years \& 50 years old high schools in the state of Odisha.

$\square$ It has also partnered with Agastya International Foundation for teaching of Mathematics and Science, and with Jolly Learning Limited, UK for English literacy in young children across Odisha.

\section{Challenges of 'Mo School Abhiyan': Data from the Field}

Despite all the positive aspects of 'Mo School Abhiyan', the challenges make it a difficult task to provide a fair platform for equal distribution of resources for the holistic development of entire public-school education in Odisha. The pitfall of the project could be realized under the following dimensions which were based on the information received from the informal interviews with alumni which shown in Fig. 1.

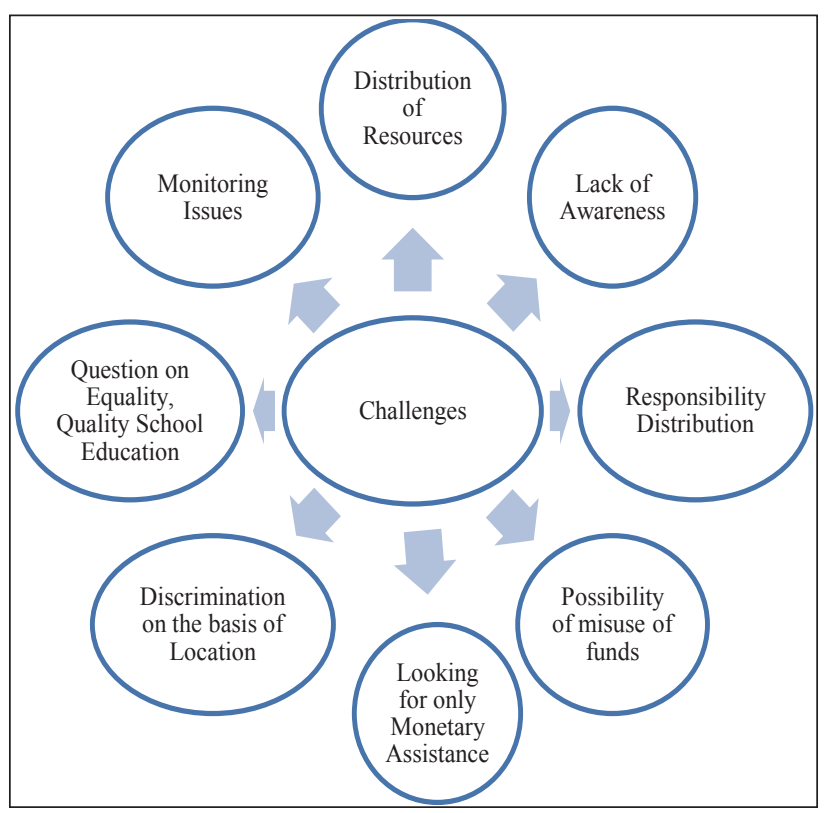

Fig. 1: Challenges observed throughout 'Mo School Abhiyan' 
Distribution of Resources: One of the respondents has shown despair in the distribution of allocation of grants by the Government on the basis of the alumni donation whereas it should be done in accordance with the need of the school particularly in the respondent's view. The monetary grant by the Government is only for those schools who have received any financial donations from the alumni. This criteria of providing funds for reformation of school education creates a divide between the haves and have-nots of financial donation from alumni. The financial support from the Government is then distributed asymmetrically among all the schools. This unequal distribution of resources promotes inequality among schools and has become the problem of the programme.

Lack of Awareness: Awareness is a vital part of any programme to be successful. In this project of 'Mo School Abhiyan', awareness should be among the alumni, community members, teachers, head of the institutions and others involved in the programme. The data collected from many of the stakeholders clearly indicate that there is no proper awareness of this programme among them, which might be causing difficulties in the achievement of the initiative at some places. Most of the stakeholders thought that the initiative is only for collection of money from the alumni to bring some infrastructural reformations in school. They had no idea about the five pillars of the project.

Responsibility Distribution: The responsibility of creating awareness among the alumni and the community members is upon the teachers at the school which creates extra burden on teachers or the head teacher at the schools. It has been observed that the teachers visited every doorstep of the villagers to collect money for this project 'Mo School Abhiyan' which was really unusual practice on the part of the teachers creating hindrance in development of school education.

Discrimination on the basis of Location: The responses from the alumni and the community towards 'Mo School Abhiyan' initiative is based upon the location of the school as well as how many alumni were well settled with having high economic status in the society. One of the respondents, as a teacher reacted critically on this aspect as a drawback mentioning that it has been observed that schools which are present in the remote/rural areas, where people have low literacy rates and low socioeconomic status, received very negligible amount of donations. Thus, the Government support for the reformation of school education in such areas were despairing. This might lead to create discrimination of resource distribution at different localities.

Possibility of misuse of funds: In the informal interview, one of the respondents strongly opposed the programme reporting of some unfair utilization of funds by the teachers. The monetary transition may be a factor for promoting misuse in terms of collection, utilization, distribution etc. The teachers communicated with the alumni and other community members about the programme of 'Mo School Abhiyan' as to contribute money for improving the school education in the infrastructural aspect, whereas they are unaware of other kinds of contributions they could do without monetary donations. Here difficulties might be seen in terms of the misinformation shared by the teachers and misuse of the financial resources from the donors as well as from the Government.

Looking for only Monetary Assistance: Looking forward to monetary assistance may be one of the main issues during implementation of the initiative. The lack of awareness among various stakeholders and the improper practice are the underlying causes of looking at the financial contributions only. As an alumnus and a teacher as well, the interviewee has observed some traces of unfair practices in financial transactions under 'Mo School Abhiyan'.

Question on Equality, Quality School Education: The interviewee as a stakeholder of the school and part of the community had an argument on the role and responsibility of the Government for developing school education for holistic development of learners. The School Education ecosystem must provide quality education equally for all. This includes the holistic development of learners with an inclusive infrastructure catering all the needs of learners and for advancement of knowledge in the era of knowledge explosion. The responsible Government should be accountable to provide the opportunities equally to all schools for the reformation of the school education holistically. In this case of 'Mo School Abhiyan', the resources allotted to schools who received financial contributions from alumni only. That leads to the raise of question on the accountability of Government in providing 
resources equally for the reformation of School Education.

Monitoring Issues: Some respondents had raised the question on the credibility of the programme. The novel initiative requires a well-structured framework for monitoring. The data showed that there was no proper monitoring mechanism observed since the initiation of the programme of 'Mo School Abhiyan'. There is no clear data available in the official website about the progress of the 'Mo School Abhiyan' and the updates were pending at most of the sections. Lack of monitoring may have created the loss of faith in the programme. The issue of proper utilization of the financial contribution was developing widely among the alumni and the community members due to the nonappearance of proper monitoring at different levels.

\section{Perspectives of the Stakeholders on 'Mo School Abhiyan'}

Community: The areas populated with low socio-economic conditions as well as low literacy could not realize the requirement of this kind of initiative. They practically have no further scope of education. They even did not know much about the advancement of technology and accountability for the quality education by the responsible Government. Other responses from the community where most of the stakeholders belong to high literate and a high socio-economic status appreciated the concept and initiation of 'Mo School Abhiyan' and promoted this in different social media.

Teacher: The responses from the teachers are not very satisfactory on the basis of overwhelming burdens.

Head teacher: Positive response from head teacher has been observed but also showed the frustration towards the system as that is not updating the data provided. One of the head teacher as a respondent told, "The initiative is quite good. I was very excited to do something to my alma-mater".

Education officer: The programme was going smoothly and at some point, teachers were donating the financial support to get the grant from the Government which was not the underlying concept of the programme.

Learners: The responses from the learners where they got much better scope for learning than the previous school set-up, are happy and looking forward for more.

Alumni: Responses from the alumni who have contributed were seeking proper utilization of their contributions and a proper monitoring which could accurately produce the progress reports.

One of the respondents stated critically about the initiative as, "This scheme was a trick of the Government to avoid its sole responsibility to reform School Education for the holistic development of learners".

\section{Summary and Discussion}

Alumni and the community have a great impact on the school education. The alumni can be the role model for the learners and the community could be the support system for the school as a miniature society. It was justified from the policies and guidelines of Government institutions who are responsible for ensuring the quality education at different levels of educational institutions. National Education Policy-2020 had also emphasized the role of alumni and community members as support to bring improvement in school education. The stakeholders of the system of education are interrelated and have the potential to make the school legendary. To study the importance of alumni in school education with respect to the innovative initiative 'Mo School Abhiyan' was quite relevant in this study.

This study was designed to evaluate the programme of 'Mo School Abhiyan'. Case study research methodology was adopted to evaluate the programme using multiple case studies. The newness of the programme was requiring a multifaceted framework of monitoring the programme from different angles and from all categories of stakeholders at the school education ecosystem. The participants were interviewed informally by open-ended questions and the data collected from that were then triangulated by other stakeholders. As incorporating the data, many of the arguments by the participants were observed unsatisfactory towards the monitoring mechanisms of the programme. It was quite a time-consuming process to have informal interviews with open ended questions. There should be a good monitoring mechanism developed so that the pitfalls could be identified at large with a shorter period of time. 
More research should be done where the chances of misuse was observed or where most of the stakeholders have shown dissatisfaction towards the programme. Then an in-depth study could be carried out to evaluate the lacun as for successful implementation of the programme.

The concept of 'Giving Back' where the alumni got the scope of knowledge and experience that was the alma-maters, was the foundational objective of 'Mo School Abhiyan'. The concept of 'Mo School Abhiyan' emerged out of the alumni's gratitude towards their alma-maters and willingness to contribute for the improvement of the education in the schools of Odisha, India. The Government of the state Odisha responded to this desire of the alumni and created a platform where the alumni can contribute to their alma-mater from anywhere by the project 'Mo School Abhiyan'. In support of monetary contributions, the initiative was partnered with the state Government with the support of granting two times the contribution of finance for improving the school education of Odisha. But the rise of different issues has created hindrance for the implementation of the programme. The issues were about the equality of distribution of resources, burden on the part of teachers, chances of misuse, lack of awareness, and issues relating to the monitoring of the programme reported from the data collected. Some suggestive measures have also evolved from the analysis of the data discussed in the suggestion part of the report.

\section{Suggestions}

The successful implementation of any initiative depends on the dutifulness of the responsible participants, realization of the objectives and awareness among the stakeholders in the educational sector particularly. Some suggestions could be taken into consideration from the data analyzed and the pitfalls of the 'Mo School Abhiyan' initiative, which are as follows;

The assessment of the needs of each school should be done firsthand.

$\square$ Government should take the responsibility of providing resources as per the requirements of school.

$\square$ Awareness must be created among all the stakeholders and assessment of the awareness should be there to eradicate misinterpretation. $\square$ There should be a proper review of the expenses of the monetary assistance given to the schools.

$\square$ A monitoring mechanism should work with multi-faceted dimensions to check the pitfalls of the whole programme from different aspects.

$\square$ There should be a conscious effort for updating accurate data on the official website regarding every aspect of school education.

\section{CONCLUSION}

The involvement of community to the school system is not a newer one but the concept of connecting the alumni might be catchy considering the emotional attachment to the school. The eminent persons having a reputation in the society as alumni have greater ability to influence the students of the same alma-maters where they got their education. This acts as a catalyst for motivating the learners and improving the school education as well. Alumni can also be helpful in providing valuable financial, intellectual, and human resources. They can provide the students new technologies, better facilities, and experiences from their knowledge. But the issues emerged in a new initiative taken as in the 'Mo School Abhiyan' should be catered before it affects the great objectives of revamping the school education ecosystem with the inclusion of alumni as a means of great resource.

\section{REFERENCES}

ANI. 2021. Hrudanand Prusty, an engineer introduces Smart Class and online learning in govt. school in Odisha. ANI. https://www.aninews.in/news/national/ general-news/hrudanand-prusty-an-engineer-introducessmart-class-and-online-learning-in-govt-school-inodisha20210717182046/

Das, P. 2021. Odisha's 'Mo School' programme, involving community and individual participation to strengthen the school ecosystem, receives overwhelming response. Frontline. https://frontline.thehindu.com/dispatches/ odishas-mo-school-programme-involving-communityand-individual-participation-to-strengthen-theschool-ecosystem-receives-overwhelming-response/ article33780907.ece

Gay, L.R., Mills, G.E. and Airasian, P.W. 2014. Educational research: Competencies for analysis and application $\left(10^{\text {th }}\right.$ Edn.). London: Pearson Education.

Mohanty, D. 2021. Meet organisations bridging Odisha's great digital divide to teach students. Hindustan Times. https://www.hindustantimes.com/india-news/meetorganisations-bridging-odisha-s-great-digital-divide-toteach-students-101625467929048.html 
Moody, J. 2020. 10 Colleges Where the Most Alumni Donate. U.S. News. https://www.usnews.com/education/bestcolleges/the-short-list-college/articles/universities-wherethe-most-alumni-donate

National Assessment and Accreditation Council. 2020. Institutional Accreditation- Revised Manual for Universities. http://www.naac.gov.in/resources/ publications/manuals

National Education Policy. 2020. Ministry of Human Resources and Development. https://www.education.gov. in/sites/upload_files/mhrd/files/NEP_Final_English_0. pdf

Shakil, A.F. and Faizi, W.N. 2012. "The Importance of Alumni Association at University Level in Karachi, Pakistan", Education, 2(1): 25-30.

Srinivasan, M. 2019. The benefits of a strong alumni network. The Hindu. https://www.thehindu.com/education/thealma-mater-connect/article29360001.ece

Tulankar, S. and Grampurohit, B. 2020. Role of alumni as stakeholders in enhancing quality education[conference presentation]. Sustaining Quality: NAAC New Guidelines 2017 conference, Bhandup, Mumbai. https://www. researchgate.net/publication/341650267_Role_of_alumni_ as_stakeholders_in_enhancing_quality_education
The New Indian Express. 2021. 'Mo School' campaign: Odisha $\mathrm{CM}$ requests $\mathrm{HC}$ judges, Union Ministers, lawmakers to adopt schools. The new Indian Express. https://www. newindianexpress.com/states/odisha/2021/jan/25/moschool-campaign-odisha-cm-requests-hc-judges-unionministers-lawmakers-to-adopt-schools-2254893.html

Times of India. 2021. 33,000 schools join Mo School campaign. Times of India. https://timesofindia.indiatimes.com/city/ bhubaneswar/33000-schools-join-mo-school-campaign/ articleshow/82340839.cms

TNN. 2021. 'Mo School' to start massive monitoring drive. Times of India. https://timesofindia.indiatimes.com/ home/education/news/mo-school-to-start-massivemonitoring-drive/articleshow/81342682.cms 
